\title{
Recomendação de Conteúdo em um Ambiente Colaborativo de Aprendizagem Baseada em Projetos
}

\section{Title: Content Recommendation in a Collaborative Project-based Learning Environment}

Otávio Costa Acosta

Universidade Federal do Rio

Grande do Sul (UFRGS)

ocacosta@inf.ufrgs.br

\author{
Eliseo Berni Reategui \\ Universidade Federal do Rio \\ Grande do Sul (UFRGS) \\ eliseoreategui@gmail.com
}

\author{
Patrícia Alejandra Behar \\ Universidade Federal do Rio \\ Grande do Sul (UFRGS) \\ pbehar@terra.com.br
}

\begin{abstract}
Resumo
O presente trabalho tem como objetivo investigar de que modo uma atividade de Aprendizagem Baseada em Projetos (ABPr), apoiada por um ambiente tecnológico desenvolvido para este fim, pode contribuir no desenvolvimento de projetos por meio de recursos de recomendação de conteúdo e ferramentas de colaboração entre pares. Para isto é utilizado uma abordagem ativa de aprendizagem, a ABPr, definida como um método de aprendizagem centrado no aluno e que enfatiza atividades para o desenvolvimento de projetos. Para a aplicação do método proposto foi estruturada uma atividade educacional, que consiste no desenvolvimento de um projeto a partir das investigações dos alunos em relação a um tema proposto pelo professor. $O$ desenvolvimento deste projeto se inicia e termina em sala de aula, entretanto as fases intermediárias podem ocorrer em outros locais. Para a execução da atividade foi desenvolvida uma ferramenta que incentiva a colaboração entre os alunos. Isto permite uma maior interação entre os participantes e também a possibilidade dos alunos colaborarem nos projetos uns dos outros. Durante o desenvolvimento de seus projetos, a ferramenta sugere materiais complementares relacionados ao assunto tratado, como forma auxiliar os alunos em seus processos investigativos. Para a avaliação do trabalho proposto foi estruturada uma pesquisa quali-quantitativa, na modalidade estudo de caso, com coleta de dados por meio da análise de projetos, registro de atividades, questionários e entrevistas. Os resultados obtidos através dos experimentos realizados demonstraram que a atividade educacional proposta por este trabalho contribuiu de forma significativa para o desenvolvimento de projetos e para uma maior interação entre os alunos.
\end{abstract}

Palavras-Chave: Aprendizagem Baseada em Projetos; Colaboração; Sistemas de Recomendação

\begin{abstract}
The present work aims to investigate how a Project-based Learning (PBL) activity, supported by a technological environment developed for this purpose, can contribute to the development of projects by means of content recommendation resources and collaboration tools among peers. For this reason, an active learning approach is used, PBL, defined as a student-centered learning method that emphasizes activities for project development. For the application of the proposed method an educational activity was structured consisting in the development of a project based on students' investigations related to a topic proposed by the teacher. The development of this project starts and ends in the classroom, but the intermediate stages can occur in other places. For the execution of the activity, a tool was developed for fostering collaboration between students. For the execution of the activity, a tool was developed for fostering collaboration between students. This allows a higher interaction between participants and the possibility of students to collaborate on each other's projects. During the development of their projects, the tool suggests additional materials related to the subject at hand, as a way to assist students in their research processes. For the evaluation of the proposed work, a quali-quantitative case study was structured, with data collected through computer logs, the analysis of the students' projects, questionnaires and interviews. Results from the experiments performed showed that the educational activity proposed by this work has contributed significantly to the development of projects and for a higher interaction among students.
\end{abstract}

Keywords: Project-based Learning; Collaboration; Recommendation Systems

Cite as: Acosta, O. C., Reategui, E. B., \& Behar, P. A. (2018). Content Recommendation in a Collaborative Project-based Learning Environment (Recomendação de Conteúdo em um Ambiente Colaborativo de Aprendizagem Baseada em Projetos). Brazilian Journal of Computers in Education (Revista Brasileira de Informática na Educação - RBIE), 26(1), 91-111. DOI: 10.5753/RBIE.2018.26.01.91 


\section{Introdução}

Um dos grandes desafios atuais na área da Educação está relacionado às possibilidades de implantação, em sala de aula, de práticas que favoreçam os processos de aprendizagem através do uso da tecnologia. A aprendizagem depende de um processo construtivo que ocorre por meio de construções e reconstruções dos sistemas de significação e lógicos de um indivíduo. Para que ocorram estes processos de construção/reconstrução é fundamental que este indivíduo possa interagir com objetos reais bem como com outros sujeitos (Piaget, 1977). Desta forma, a importância em dominar e interagir com as tecnologias existentes que visam facilitar estes processos de aprendizagem também é essencial nos dias atuais (Lefrançois, 2008), pois muitas vezes os métodos tradicionais de ensino se mostram pouco eficazes na formação de estudantes. O pensamento crítico, a capacidade de resolução de problemas, a colaboração e a tomada de decisão são habilidades vitais para a formação de cidadãos no mundo contemporâneo. Portanto, esta dificuldade motivou a busca por abordagens educacionais que procuram favorecer $o$ crescimento pessoal dos estudantes.

Uma abordagem que contempla o desenvolvimento de atividades centradas nos alunos é conhecida como Aprendizagem Ativa, a qual consiste em um conjunto de práticas pedagógicas que estimula os estudantes a participarem de atividades que levam à reflexão, ao questionamento, à busca pela compreensão de conceitos e a como aplicá-los em um contexto real. Esta prática exige que os alunos avaliem regularmente seu próprio grau de compreensão sobre determinado assunto e sua habilidade na utilização deste conhecimento (Michael, 2006).

Alguns enfoques educacionais utilizam-se de métodos ativos para promover atividades interativas em sala de aula em que os alunos desenvolvem suas próprias linhas de investigação. Dentre eles podemos destacar a Aprendizagem Baseada em Projetos (ABPr). Neste método, os estudantes devem tomar suas próprias decisões quanto ao desenvolvimento de projetos que envolvem questões contextualizadas em sua realidade, com o intuito de motivar os alunos para que realizem investigações de longo prazo de maneira autônoma e/ou conjunta (Markham, Larmer, \& Ravitz, 2008).

Em um estudo comparativo, Gormally, Brickman, Hallar, e Armstrong (2009) demonstraram como estudantes de graduação que seguiram as definições dos métodos ativos obtiveram um melhor desempenho no que diz respeito a suas habilidades científicas e seu conhecimento na área de ciências, quando comparados com estudantes que seguiram metodologias mais tradicionais de ensino e aprendizagem. Entretanto, para que a implementação de métodos ativos de aprendizagem não deixe os alunos sem nenhuma orientação durante as investigações, o proponente deve elaborar um processo estruturado para o desenvolvimento das atividades, disponibilizando recursos condizentes com a tarefa.

A busca por métodos e ferramentas de apoio à aprendizagem ativa resulta em uma profusão de trabalhos descrevendo atividades, práticas pedagógicas e ambientes computacionais que tiveram algum tipo de resultado positivo no que diz respeito aos processos de ensino e aprendizagem. Contudo, apesar do caráter atraente das abordagens de aprendizagem ativa, a pesquisa na área também demonstrou que a falta de instrução guiada algumas vezes pode trazer resultados não tão satisfatórios (Kirschner, Sweller, \& Clark, 2006). Com base nessas considerações, é possível perceber a necessidade de avançar nas pesquisas sobre ferramentas e métodos ativos de aprendizagem, considerando-se os limites entre a proposta de atividades com estrutura e objetivos precisos, e a liberdade que os alunos devem ter para o desenvolvimento de suas investigações.

No intuito de propor uma alternativa ancorada em um método de aprendizagem ativa, este trabalho definiu como objetivo principal investigar de que modo uma atividade de Aprendizagem Baseada em Projeto, apoiada por um ambiente tecnológico desenvolvido para 
este fim, pode contribuir no desenvolvimento de projetos por meio de recursos de recomendação de conteúdo e ferramentas de colaboração entre pares. Para isto foi estruturado um estudo com a abordagem quali-quantitativa, na modalidade de estudo de caso com coleta de dados por meio da análise de projetos, registro de atividades (logs de dados), questionários e entrevistas.

A proposta de atividade definida para este estudo é apoiada por uma ferramenta que guia o aluno no desenvolvimento de um projeto, no entanto, sem limitar sua liberdade na busca por informações e/ou caminhos a serem seguidos por suas pesquisas. A ferramenta desenvolvida propõe o emprego de um sistema de recomendação capaz de identificar materiais na internet relacionados aos projetos dos alunos, apoiando-os assim no aprofundamento, ampliação ou até mesmo contestação de suas investigações. Nesta atividade, surge ainda a necessidade de proporcionar aos estudantes um espaço para troca de ideias, dúvidas e diferentes pontos de vista, promovendo a interação entre pares com vistas ao desenvolvimento de pesquisas e projetos.

As demais seções deste trabalho estão organizadas da seguinte forma: a Seção 2 aborda a área de Aprendizagem Ativa e Aprendizagem Baseada em Projetos, a Seção 3 trata sobre Aprendizagem Colaborativa mediada pela Tecnologia e a Seção 4 sobre Sistemas de Recomendação. A Seção 5 descreve a metodologia de pesquisa e a Seção 6 apresenta os resultados obtidos através dos experimentos realizados. Por fim, a Seção 7 apresenta as considerações finais do trabalho.

\section{Aprendizagem Ativa e Aprendizagem Baseada em Projetos}

A Aprendizagem Ativa pode ser definida como um conjunto de práticas pedagógicas que abordam a questão da aprendizagem pelos alunos sob uma perspectiva diferente das técnicas tradicionais, nas quais se espera que o professor "ensine" o conteúdo e o aluno o "aprenda". O termo pode significar para alguns um conceito redundante, uma vez que é impossível aprender passivamente. Muitos professores afirmam que toda a aprendizagem é intrinsecamente ativa e que os alunos são ativamente envolvidos enquanto assistem apresentações formais em sala de aula (Michael, 2006). No entanto, o significado real da aprendizagem ativa sugere que os alunos devem fazer mais do que apenas ouvir, eles devem ler, escrever, discutir, analisar e resolver problemas.

$\mathrm{Na}$ aprendizagem ativa, entende-se que o aluno seja o centro do processo de aprendizagem e não somente um receptor de informações, com menos ênfase na apresentação de informações e mais no desenvolvimento das habilidades dos alunos. Desta forma, ele deve engajar-se na construção do conhecimento, focando em objetivos específicos de maneira proativa. Neste contexto, as atividades propostas pelo professor devem permitir que, além de serem resolvidas, os alunos possam pensar e refletir sobre o que estão fazendo, dando mais ênfase na exploração que eles fazem de suas próprias atitudes e de seus próprios valores (Bonwell \& Eison, 1991).

Apesar disto, grande parte dos professores ainda tem o receio da aplicação de métodos ativos em sala de aula. Isso ocorre devido algumas limitações conhecidas e que muitas vezes dificultam a aplicação destes métodos como, por exemplo, a falta de incentivo e de recursos por parte das escolas. Estes obstáculos, contudo, devem ser observados e podem ser ultrapassados através de um planejamento bem elaborado e consistente para a atividade proposta.

$\mathrm{O}$ conceito de aprendizagem ativa envolve diferentes abordagens que têm em comum a característica de centrar o processo de aprendizagem no aluno, privilegiando o desenvolvimento de sua autonomia na condução das atividades propostas. Dentre estas abordagens podemos destacar a Aprendizagem Baseada em Investigação, utilizada no Projeto SMILE (Stanford Mobile Inquiry-based Learning Environment) (Seol, Sharp, \& Kim, 2011). O SMILE é um 
projeto baseado em uma abordagem particular com o intuito de transformar uma sala de aula tradicional em um ambiente de aprendizagem interativo, engajando os alunos em atividades voltadas ao desenvolvimento do raciocínio crítico e à resolução de problemas. A proposta do SMILE utiliza-se de uma abordagem que estimula alunos a facilmente criarem questões de múltipla escolha através de dispositivos móveis, relacionadas a um determinado assunto escolhido pelo professor. Posteriormente, estas questões são compartilhadas entre todos que estão participando da atividade, para que sejam resolvidas. Embora tenha servido como base inicial dos estudos, a evolução da pesquisa deste trabalho, contudo, permitiu compreender que as ferramentas disponíveis no projeto SMILE poderiam ser adaptadas para um melhor enquadramento com as abordagens ativas de aprendizagem.

Portanto, para este trabalho foi utilizada a abordagem de Aprendizagem Baseada em Projetos (ABPr) que consiste em uma estratégia ou metodologia educacional, que promove a realização contextualizada e planejada de tarefas que geralmente envolvem situações reais (Markham, Larmer, \& Ravitz, 2008). Tem por objetivo estruturar o processo de resolução de problemas, criação de serviços ou desenvolvimento de produtos, fazendo destes um processo de aprendizagem. Inicia através de questões norteadoras instigantes, abrange conteúdos interessantes com o intuito de motivar as investigações de longo prazo de maneira autônoma e/ou conjunta. (Larmer \& Mergendoller, 2010).

Os autores supracitados destacam ainda que, com o avanço das pesquisas em neurociências e em psicologia, foi possível compreender melhor os modelos cognitivos e comportamentais de aprendizagem. Evidenciou-se que cognição, ação e contextos de aprendizagem estão inseparavelmente relacionados, em que a aprendizagem é, em parte, uma atividade social e ocorre em um contexto de cultura, comunidade e de experiências anteriores. Markham (2012) ainda enfatiza que a ABPr deveria ser vista como uma filosofia de ensino e aprendizagem, ao invés de uma estratégia educacional, pois ela representa como será organizada a educação no futuro.

\section{Aprendizagem Colaborativa Mediada pela Tecnologia}

Com o constante avanço tecnológico, cada vez mais é possível planejar e desenvolver atividades que promovam a troca, a comunicação e a negociação entre alunos em sala de aula ou até mesmo fora dela. A utilização de recursos digitais pode ampliar o uso de novas estratégias pedagógicas apoiadas na comunicação multidirecional entre os participantes envolvidos (Lévy, 1999).

A construção colaborativa é caracterizada como qualquer atividade que se realize a partir da interação, avaliação e/ou colaboração entre pares, de forma estruturada e coordenada (Harasim, Teles, Turoff, \& Hiltz, 2005). Este tipo de construção pode ser compreendido como resultado da sintonia entre grupos de indivíduos que conseguem comparar e diferenciar seus pontos de vista, com o intuito de produzir novos conhecimentos (Guitert \& Giménez 2000).

Todas as ações de um indivíduo em um ambiente colaborativo dependem da participação de outro para alcançar novas construções e aprendizagens. Sem a participação de cada sujeito envolvido, a troca é inexistente. Nesta perspectiva, é importante observar que as intervenções do professor devem ser ágeis e frequentes. Muitos alunos que empregam os recursos tecnológicos no desenvolvimento de atividades tendem a tornarem-se mais exigentes, com expectativas maiores quanto aos recursos utilizados bem como quanto às propostas de atividades (Gosper, Malfroy, \& McKenkie, 2013).

As frequentes interrupções na comunicação entre alunos/professor podem causar o desconforto pela falta de entendimento e diminuição da participação do aluno. Quando ele 
acessa uma atividade a partir de um recurso digital e percebe a falta de dinâmica e de participação de outros colegas e do professor, pode sentir-se desestimulado, como se fosse o único a empenhar-se no desenvolvimento da atividade. Diante disto, ressalta-se que o envolvimento e participação do docente são determinantes para o sucesso de uma prática educacional colaborativa, apoiada por recursos tecnológicos (Paloff \& Prat, 2004).

Para a plena promoção de uma atividade colaborativa, é importante que todos os participantes tenham conhecimento da proposta do trabalho e dos objetivos a serem obtidos. No momento em que a troca entre os alunos torna-se um dos objetivos de uma atividade, é fundamental que estas se apoiem em um processo coletivo em que a interação entre os participantes seja uma prática constante e que sirvam de base para sucessivas construções.

Portanto, para que seja possível o desenvolvimento de atividades colaborativas entre alunos através de recursos digitais, é necessária a disponibilização de um ambiente virtual que comporte estas trocas. $\mathrm{O}$ uso de espaços destinados para contribuições pessoais podem auxiliar ainda o fortalecimento do sentimento de pertencer ao grupo e de afetividade, refletindo assim em importantes benefícios sociais que permitem o avanço das produções coletivas.

\section{Sistemas de Recomendação}

Com o contínuo aumento da inclusão digital e a consequente facilidade de acesso a grandes quantidades de informações, fica cada vez mais difícil a tarefa de escolha de conteúdos dentre as diversas opções disponíveis na web, principalmente para um indivíduo que não tenha experiência suficiente em determinado assunto. Para minimizar esta situação, é comum que a pessoa se baseie em recomendações. Assim, podemos dizer que os Sistemas de Recomendação (SR) buscam replicar este processo de indicação já bastante conhecido na relação social entre seres humanos (Resnick \& Varian, 1997).

Os Sistemas de Recomendação consistem em ferramentas e técnicas que fornecem sugestões de itens que possam ser de interesse de um usuário, conforme o contexto ao qual estão inseridos. Estas áreas destinadas às sugestões visam apoiar os usuários em processos de tomada de decisão, compra de itens, músicas para ouvir ou notícias para ler, dentre outros e são amplamente utilizados na área de negócios, principalmente no comércio virtual (e-commerce). Empresas como Amazon, Google e, mais recentemente, a Netflix são reconhecidas pelo uso destes mecanismos para obter vantagem competitiva diante de seus concorrentes (Ricci, Rokach, \& Shapira, 2015).

Mais recentemente, os sistemas de recomendação também passaram a ser utilizados para fins educacionais, como forma de auxiliar os alunos na busca de materiais que possam ajudá-los durante o processo de aprendizagem (Shuib, Baiti, Normadhi, Alias, \& Binti, 2015). No contexto educacional, os itens recomendados geralmente consistem em artigos, livros, autores e objetos de aprendizagem, específicos para um determinado assunto e que podem ser encontrados na web e/ou em repositórios digitais. Pesquisas utilizando um mecanismo de recomendação demonstraram que um ambiente virtual de aprendizagem, com a capacidade de sugerir conteúdos personalizados para cada aluno, tiveram um impacto positivo na aprendizagem (Reategui, Boff, \& Campbell, 2008; Rifon, Rodriguez, Roriz, Gago, \& Iglesias, 2013).

Os autores Drachsler, Hummel, e Koper (2008) focam na redução da sobrecarga de informação e abordam sobre a utilização de sistemas de recomendação personalizados para atividades de contexto de e-learning, com ênfase em redes de aprendizagem para todos os níveis de ensino. Seguindo na linha de e-learning, o sistema de recomendação social QSIA visa melhorar o compartilhamento de conhecimento entre os alunos em um sistema de aprendizagem online, a partir da avaliação dos itens pelos próprios alunos (Rafaeli, Dan-Gur, \& Barak, 2008). 
Já o sistema proposto por Cazella, Reategui, e Behar (2010) propõe a recomendação de objetos de aprendizagem utilizando um mecanismo de filtragem colaborativa baseado nas competências dos alunos. O modelo permite que os estudantes recebam recomendações de materiais não somente baseados em seus interesses, mas também sobre as competências específicas que precisam ser desenvolvidas.

Como base nestes estudos, optou-se em integrar um Sistema de Recomendação, utilizando a técnica de filtragem baseada em conteúdo, para a sugestão de materiais de apoio que possam contribuir com os processos investigativos de um aluno. Estes processos são centrais na abordagem de Aprendizagem Baseada em Projetos, que têm como características relevantes: autonomia para planejar e desenvolver as atividades investigativas; a colaboração entre alunos com propósito de instigar a discussão e a troca de informações durante o desenvolvimento de projetos. O método foi baseado na pesquisa de Meurer (2014) que empregou técnica semelhante para auxiliar os estudantes no desenvolvimento de projetos na área de design. Desta forma, o presente trabalho buscou basear-se não necessariamente nas preferências do aluno, mas sim na recuperação de materiais relevantes para sua aprendizagem, de acordo com preceitos definidos sobre sistemas de recomendação em contexto educacionais.

\section{Metodologia}

Esta seção descreve a metodologia deste trabalho. Primeiramente é exposto a proposta de atividade resultante dos estudos preliminares (Acosta, Reategui, \& Behar, 2016) desta pesquisa. Em seguida é apresentada a ferramenta para utilizada para a realização da atividade e, então, é exposto o delineamento geral dos métodos de experimentação da pesquisa.

\subsection{Proposta de Atividade}

A proposta de atividade apresentada neste trabalho envolve a abordagem de Aprendizagem Baseada em Projetos, promovendo também uma maior colaboração entre os participantes. Para iniciar uma atividade os alunos devem selecionar um tema, indicado pelo professor, e logo de início se deparam com um texto introdutório (texto disparador) sobre o assunto. Este texto visa "preparar" os alunos, de forma a instigá-los a investigar assuntos relacionados ao tema exposto. O emprego de textos disparadores, imagens ou vídeos é uma prática pedagógica frequente em abordagens pedagógicas cujo foco é instigar os estudantes a se autoquestionarem (Logtemberg, Van Boxtel, \& Van Hout-Wolters, 2011) e/ou para resolução de problemas (Azer, Peterson, Guerrero, \& Edgren, 2012; Fong, O’Tolle, \& Keppel, 2007).

Além disso, os alunos também têm acesso a um grafo que representa o texto disparador. Estudos demonstram que a apresentação de um grafo com palavras-chave e relacionamentos, faz que os estudantes compreendam melhor o texto e encontrem associações que passaram despercebidas durante a leitura (Reategui \& Epstein, 2015). Estudantes que apresentam dificuldade de leitura costumam apresentar problemas em relação à compreensão e organização de informações contidas em textos. Por isso, a compreensão textual é um importante aspecto para que o aluno possa assimilar o assunto abordado e seja instigado a investigar melhor sobre ele.

As palavras-chave (nodos) apresentadas no grafo podem então ser escolhidas pelos alunos como assunto para o desenvolvimento de um projeto. Esta escolha deve basear-se nas questões que os alunos levantaram sobre o tema e que tenham interesse em pesquisá-la no intuito de elucidar suas dúvidas. Após selecionar uma palavra-chave, os alunos devem criar um texto dissertativo, na forma de projeto e, durante este processo de elaboração do projeto, os alunos recebem o auxílio de materiais de apoio que são sugeridos pelo sistema de recomendação integrado ao ambiente. Estes materiais podem ser utilizados como forma de ampliar os 
processos investigativos dos alunos durante o desenvolvimento de seus projetos (Rifon, Rodriguez, Roriz, Gago, \& Iglesias, 2013).

Durante o desenrolar da atividade, os alunos podem também contribuir com projetos de outros colegas. Com isto, além de promover a colaboração e integração entre os participantes, a atividade visa também estimulá-los a tomarem conhecimento de outros projetos desenvolvidos por seus pares e relacionados ao tema proposto pelo professor. Os principais recursos para promover estas colaborações são baseados na troca de mensagens, comentários em outros projetos e também a sugestão de projetos similares para a leitura. No caso da sugestão de projetos similares, estes podem tratar de pontos que também sejam de interesse do aluno.

Portanto, a introdução de práticas colaborativas no projeto dá a este características que promovem a interação e a construção coletiva do conhecimento, buscando favorecer processos de aprendizagem que não fiquem focados apenas em práticas individuais. A colaboração a partir da troca de ideias, dúvidas e colocação de pontos de vista distintos privilegiam tal tipo de construção (Dooly, 2008).

As teorias construtivistas também enfatizam que a aprendizagem se insere em um processo social do qual interação e colaboração fazem parte. Como enfatizado por Piaget (1973), o estabelecimento de situações que possam colocar os aprendizes em situações de conflito e cooperação são fundamentais nos processos de aprendizagem.

A Figura 1 resume o modelo proposto através do fluxo de atividades para esta atividade. Para a aplicação desta proposta foi necessário o desenvolvimento e utilização de uma ferramenta própria para este tipo de atividade. A subseção a seguir detalha a ferramenta "Toth", com exemplos de uma atividade real e outras características específicas desenvolvidas para a otimização da atividade. 


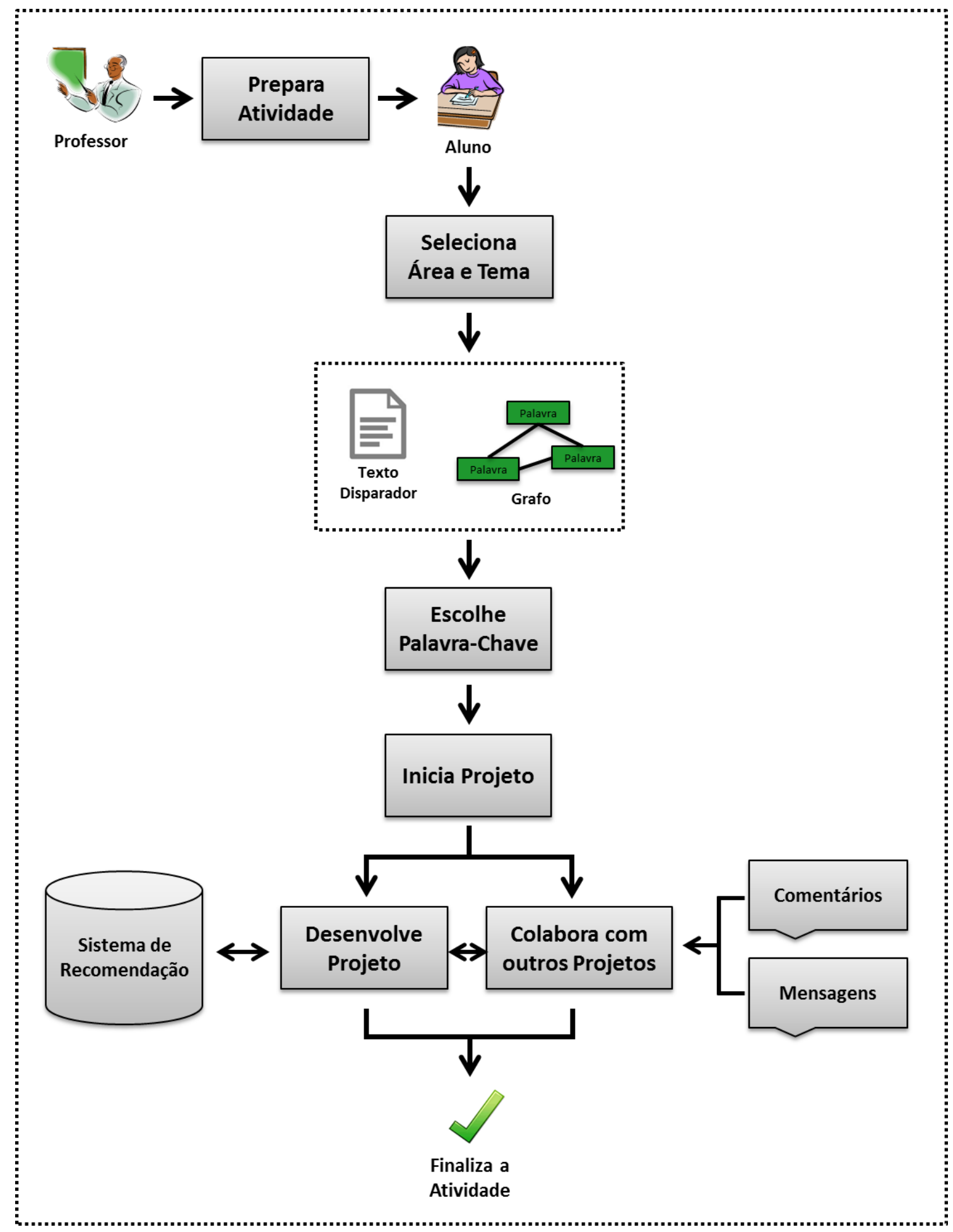

Figura 1: Resumo de atividades.

\subsection{Ferramenta Toth}

A ferramenta Toth foi desenvolvida para dar suporte a atividades de Aprendizagem Baseada em Projetos e também para auxiliar na colaboração entre os alunos durante o processo de desenvolvimento de seus projetos. Durante a escrita de um projeto, os alunos ainda recebem sugestões de materiais complementares que possam auxiliar em suas investigações.

A ferramenta foi desenvolvida com as tecnologias atuais e o principal requisito necessário para seu funcionamento é um navegador web recente que suporte tais tecnologias. A 
lista de dispositivos compatíveis vai desde dispositivos móveis até Smart $T V s$, além de, obviamente, computadores convencionais e notebooks.

Para um melhor entendimento do funcionamento da ferramenta Toth e também da atividade aplicada no estudo, o texto foi dividido em quatro módulos: (I) Módulo de Preparação do Tema, (II) Módulo de Edição do Projeto, (III) Módulo de Recomendação de Conteúdo e (IV) Módulo de Colaboração que serão explanados a seguir.

\section{(I) Módulo de Preparação do Tema}

Este módulo, destinado aos professores, permite a criação/edição de um tema. Para isto o professor deve selecionar uma área em que o tema se enquadra e inserir o título do tema. Posteriormente o professor deve inserir um texto disparador e este é enviado automaticamente para um minerador de texto (Sobek) que retorna um grafo relacionado a ele (Reategui, Epstein, Lorenzatti, \& Klemann, 2011). No grafo, os nodos representam os conceitos relevantes e as arestas representam as informações de adjacência entre os nodos. O professor pode então editar este grafo, definindo quais palavras-chave deixará disponível para os alunos escolherem como assunto para desenvolverem seus projetos. Um exemplo deste grafo é apresentado na Figura 2.

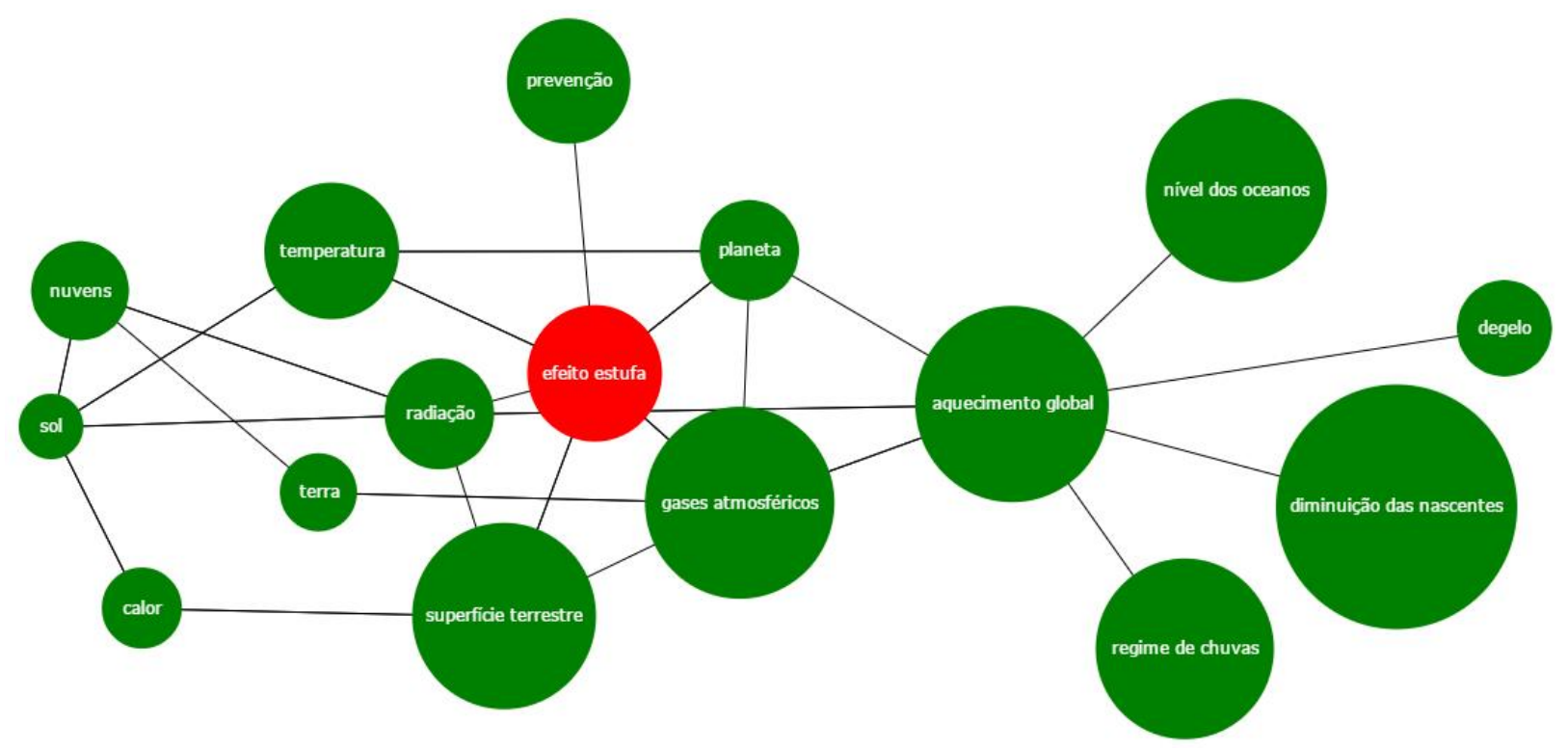

Figura 2: Grafo editado pelo professor sobre o tema "Efeito Estufa".

Cada professor pode criar vários temas, com diferentes textos disparadores associados, ficando disponíveis para serem utilizados oportunamente para a realização de uma atividade. O espaço destinado para o desenvolvimento do texto disparador é similar aos editores de texto atuais, com recursos de formatação, inserção de imagens e vídeos, hiperlinks, entre outros. Também é preciso definir o idioma (português ou inglês) para o funcionamento correto do minerador textual e definir se o tema será aberto a todos os usuários ou apenas para determinado grupo. Por fim, o professor escolhe uma data final para a conclusão dos projetos. 


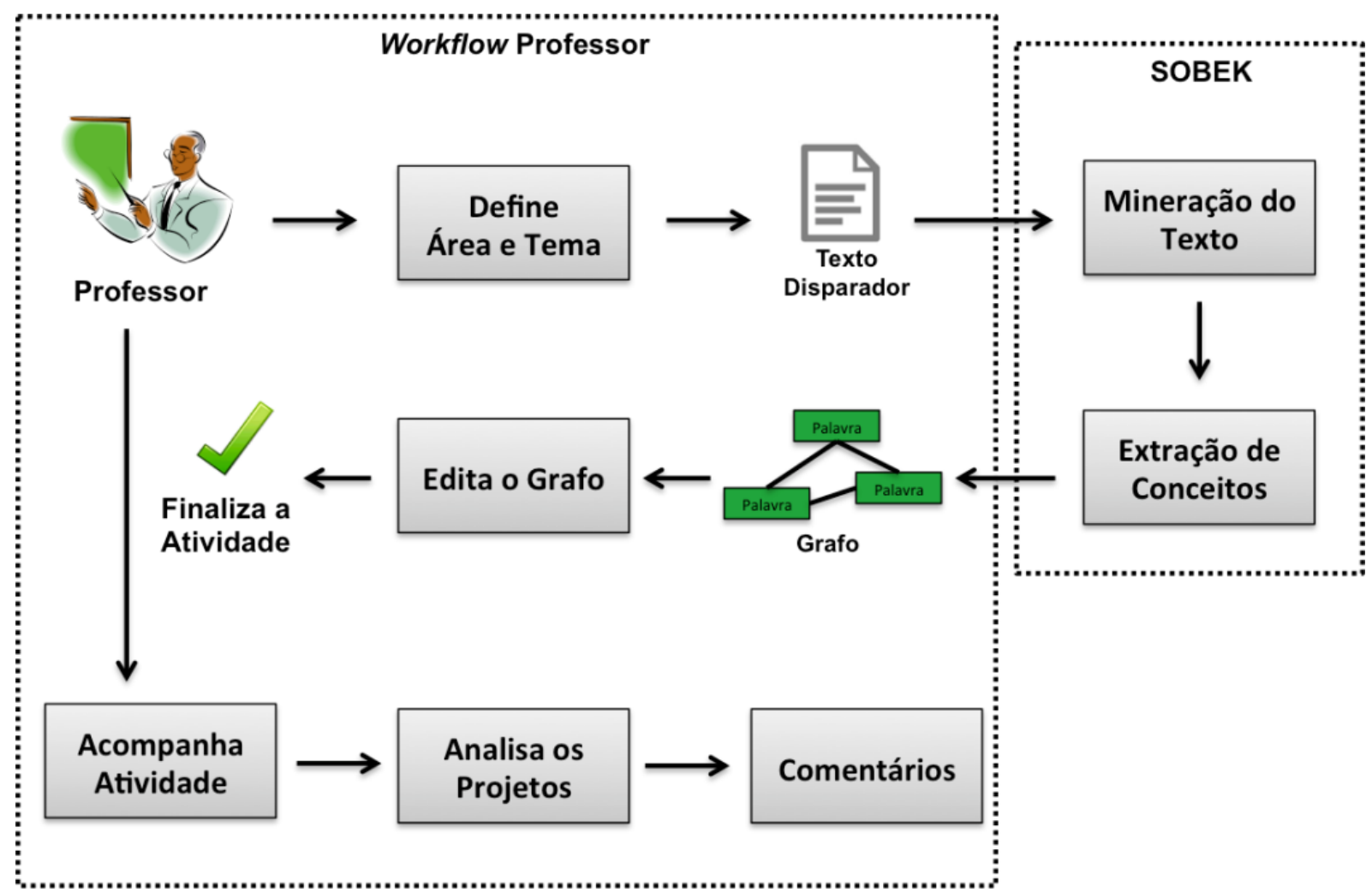

Figura 3: Fluxo de atividades do professor.

A Figura 3 resume o fluxo de atividades do professor, para criação e acompanhamento de uma atividade. Nela também é possível observar também que o professor pode interagir com os participantes através de comentários, durante o decorrer de uma atividade.

\section{(II) Módulo de Edição do Projeto}

Após os alunos acessarem um tema indicado pelo professor, lerem com atenção o texto disparador e analisarem o grafo, eles então devem selecionar uma palavra-chave que será o assunto de seu projeto. Neste momento os alunos são direcionados à uma nova página para $o$ desenvolvimento de seu texto. Nela existem dois campos de texto, um para inserir o título do projeto (questão norteadora) e outro para o desenvolvimento do projeto propriamente dito (Figura 4). O editor utilizado (TinyMCE) dispõe de diversos recursos para edição e formatação do texto. Também é possível a inserção de recursos multimídias como imagens, vídeos, imagens animadas e hiperlinks. Como uma atividade pode ser tanto síncrona, quanto assíncrona e durar vários dias ou semanas, o aluno tem a opção de salvar seu trabalho para continuá-lo em outro momento.

A ferramenta também dispõe de outro recurso importante que é o histórico de versões, gerado a cada vez que o aluno salva seu projeto. O histórico só é visível para o próprio autor do projeto e para o professor. Este recurso é importante, pois permite observar a evolução do aluno no desenvolvimento do projeto a partir da leitura de um material de apoio ou de colaborações feitas por seus colegas. Enquanto o aluno apenas salva o documento, em um primeiro momento ele não fica disponível para visualização dos demais colegas, apenas para o professor autor do tema. Sendo assim, um texto só se torna visível a todos, quando o aluno decidir "Publicar" seu projeto, permitindo assim que outros colegas possam ter acesso a ele para a leitura, reflexão e também dar suas contribuições sobre aquele assunto. 


\section{(III) Módulo de Recomendação de Conteúdo}

Durante o processo de desenvolvimento do projeto é sugerido ao aluno, em uma barra lateral, materiais de apoio referentes à sua pesquisa (Figura 4, destacado em vermelho). Como o desenvolvimento de projetos exige um esforço investigativo e expõe os alunos a sucessivos momentos de tomada de decisão, a sugestão de materiais de apoio pode oferecer conteúdos relevantes que pode influenciar positivamente o desenvolvimento de trabalho.
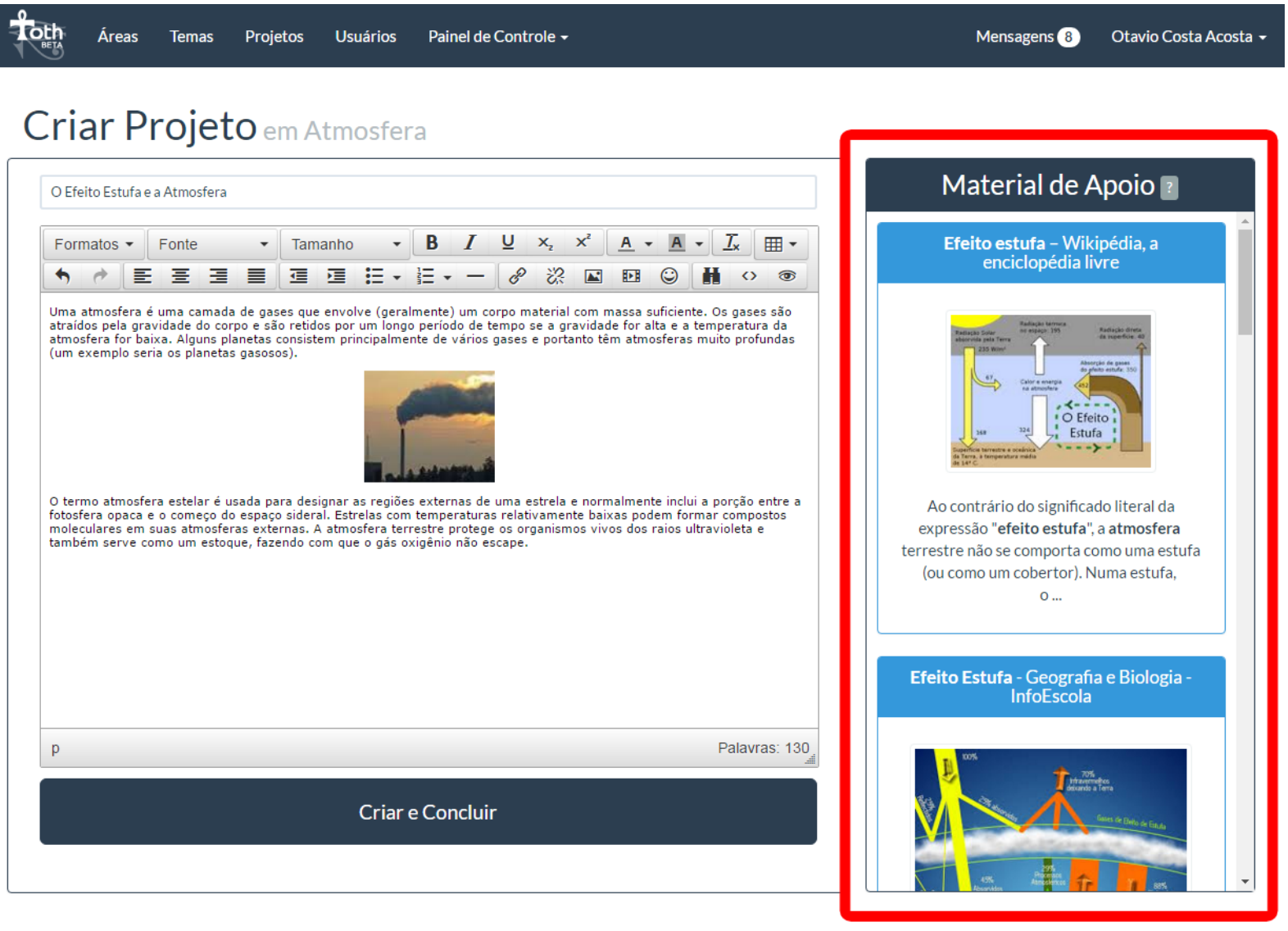

Figura 4: Edição de projeto com sugestão de materiais de apoio.

A sugestão de materiais de apoio é gerada a partir dos termos extraídos pela ferramenta de mineração de texto Sobek, integrado juntamente a um motor de busca na web. No caso deste trabalho, o mecanismo escolhido foi o Google, por atualmente ser o mais popular local de pesquisa na web. Ao iniciar um novo projeto, o aluno recebe logo no princípio sugestões de materiais de apoio (10 itens) baseados na mineração do texto disparador do tema e da palavrachave escolhida como assunto para o projeto. A ordenação desta lista é feita de acordo com a relevância definida pelo mecanismo de busca. Conforme o aluno começa a escrever seu texto, o sistema de recomendação da ferramenta Toth começa a atualizar, automaticamente, a lista de materiais de apoio relacionados ao contexto que o aluno está desenvolvendo em seu projeto. Estas atualizações na lista de materiais sugeridos acontecem em tempo real, sempre que o aluno inicia um novo parágrafo. Os tipos de materiais de apoio sugeridos podem ser desde páginas da web, artigos, livros, como também imagens e vídeos relacionados ao assunto. A Figura 5 resume o funcionamento do sistema de recomendação de materiais de apoio. 


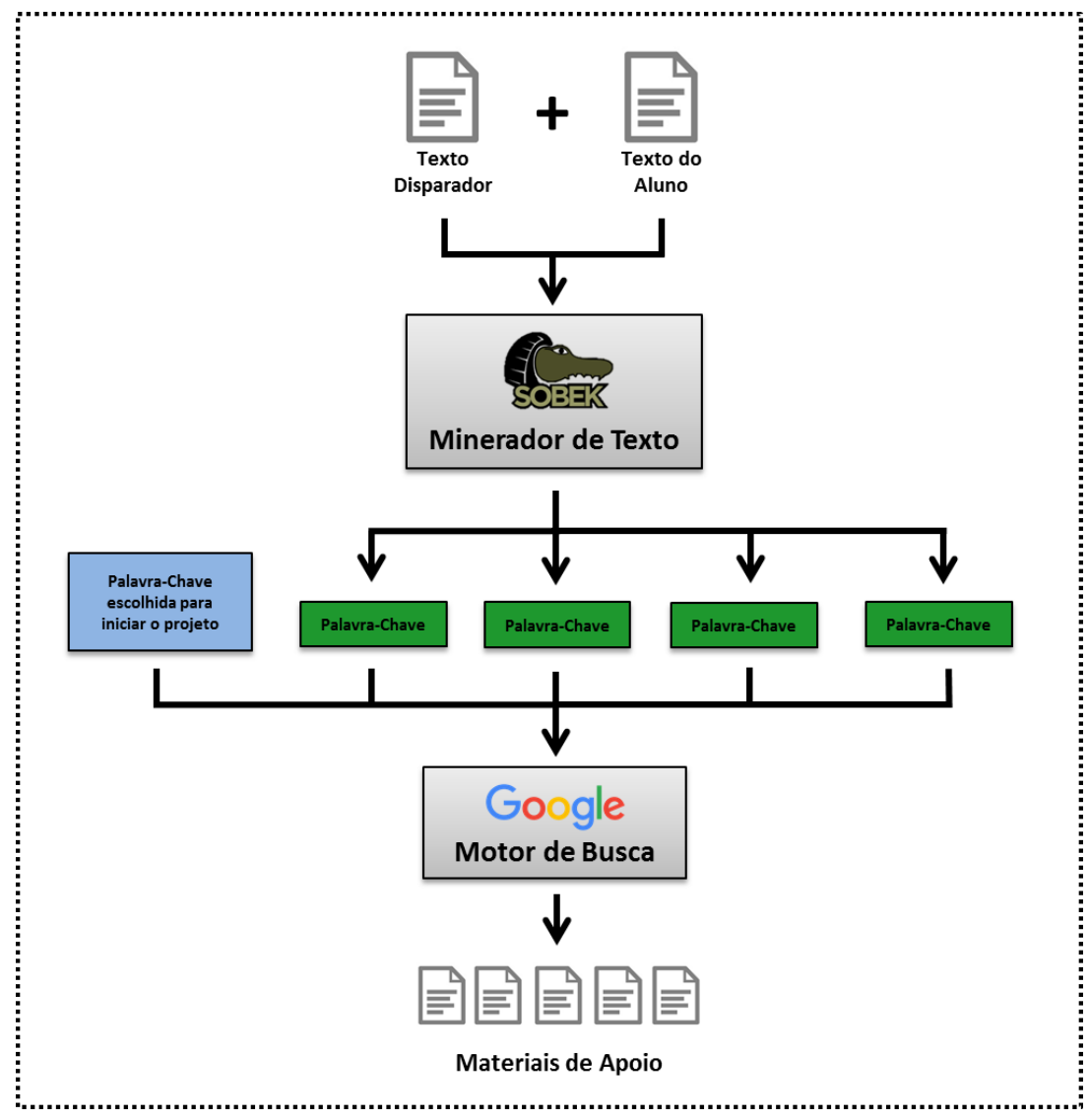

Figura 5: Sistema de recomendação de materiais de apoio.

No intuito de aprimorar as palavras-chave extraídas pelo minerador de texto, foi utilizado um etiquetador morfossintático (TreeTagger) para que fossem removidos os termos classificados morfologicamente como "verbos". Assim como a remoção das stopwords, na maioria dos casos os verbos podem prejudicar a relevância dos resultados gerados em buscas na web devido a suas várias formas de conjugação. Isto também pode acabar prejudicando o funcionamento adequado do minerador de texto, como por exemplo, ao tratar o mesmo verbo em duas formas verbais diferentes como termos distintos. Outra personalização que modifica a lista de materiais sugeridos consiste na configuração da API Google Custom Search Engine (2017). Uma API é um conjunto de padrões preestabelecidos por um software para a utilização de suas funcionalidades por outros aplicativos. No caso do Google CSE é possível dar ênfase na busca de materiais apenas em domínios específicos, como por exemplo, a Wikipédia ou algum outro repositório de objetos de aprendizagem sugerido para a atividade. Da mesma forma, essa customização pode restringir a sugestão de materiais de domínios que não sejam do interesse do criador da atividade.

\section{(IV) Módulo de Colaboração}

Durante o decorrer da atividade, a ferramenta incentiva os participantes a interagirem uns com os outros através de recursos colaborativos. Estes recursos têm por objetivo criar situações que facilitem a troca de informações e que possam contribuir para ampliar os conhecimentos do aluno. Um destes recursos ocorre sempre que o aluno salva seu projeto, em que ele é direcionado para uma página na qual é sugerido um outro projeto similar ao seu (Figura 6). Este recurso permite que o aluno tome conhecimento de outros projetos e que a análise destes lhe permita avançar em sua própria construção. 


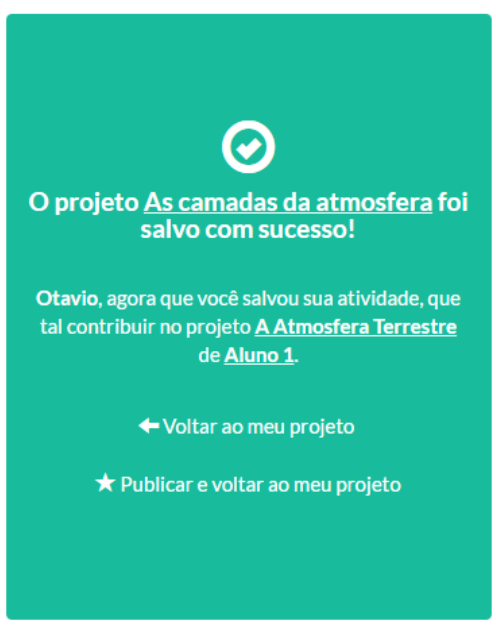

\section{A Atmosfera Terrestre}

Atmosfera é o nome dado à camada gasosa que envolve os planetas. No caso da atmosfera terrestre ela é composta por inúmeros gases que ficam retidos por causa da força da gravidade e do campo magnético que envolve a Terra. No início da formaçẫo do planeta Terra a atmosfera era composta basicamente por gases (Metano, amônia, nitrito, vapor de água $e$ dióxido de carbono) resultantes das constantes erupçôes e colisões na superficie inóspita da terra primitiva, além dos que eram expelidos por rachaduras na crosta terrestre. Então, em uma segunda fase, surgem os primeiros organismos vivos que

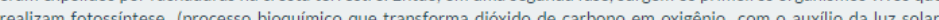
realzam fotossintese (processo bioquimico que transfor dixido de carbono em oxignio com o auxilo da luz solar, isso saturada de oxigênio. Ir...

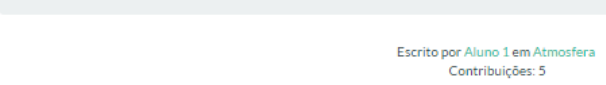

Figura 6: Sugestão de projetos similares.

Ao acessar o projeto de um colega, além de tomar conhecimento do conteúdo desenvolvido, o aluno também pode interagir com seu colega através de comentários relacionados ao assunto abordado. Para isto ele deve clicar no botão "Contribuir" e um painel de edição de texto se abre para que ele possa registrar sua contribuição no projeto. Após escrever sua contribuição sobre o projeto, o aluno será solicitado a classificar sua contribuição de acordo com as seguintes opções: "Pergunta", "Sugestão", "Curtida" e/ou "Outra" (Figura 7). Ao menos uma das opções deve ser selecionada, da mesma forma que podem ser escolhidas duas ou mais para classificar o comentário.

Como você classifica sua contribuição?

?Pergunta Sugestã̃o ßCurtida * Outra

Figura 7: Classificação de comentário.

Este tipo de classificação baseia-se na Taxonomia de Habilidades de Conversação e busca classificar frases de conversação frequentemente utilizadas para a aprendizagem colaborativa (Soller, 2001). Além destes recursos, a ferramenta dispõe também de um sistema de troca de mensagens privadas, com notificações em forma de popup em tempo real.

\subsection{Estudo Final}

Por meio desta pesquisa buscou-se investigar de que forma recursos de recomendação e colaboração poderiam contribuir para o desenvolvimento de projetos. Para o desenvolvimento desta análise foi estruturado um estudo com a abordagem quali-quantitativa. A estratégia de pesquisa foi desenvolvida na modalidade de estudo de caso, com coleta de dados realizada a partir da análise dos projetos e das atividades dos alunos, aplicação de questionários e entrevista com os professores.

O experimento final deste trabalho foi aplicado na disciplina de "Informática Básica" em duas turmas de $1^{\circ}$ ano de Ensino Médio do Instituto Federal de Educação, Ciência e Tecnologia Sul-rio-grandense (IFSul) - Campus Pelotas Visconde da Graça, nos cursos de Ensino Médio Integrado em Agropecuária e Ensino Médio Integrado em Meio Ambiente. Ao todo participaram 53 alunos de duas turmas, porém apenas 40 desenvolveram todas as atividades necessárias para a coleta de dados delineada para esta pesquisa (finalização de um projeto na ferramenta Toth e resposta a um questionário de avaliação). A atividade teve duração de quatro semanas e os alunos puderam trabalhar em seus projetos tanto em sala de aula, quanto a distância. 
O laboratório de informática onde ocorreu o experimento é equipado por 40 computadores desktop, monitores de alta resolução e conexão à internet de boa qualidade. Cada aluno tinha disponível um computador para trabalhar individualmente e não houve limitações pela falta de requisitos compatíveis para a plena execução da ferramenta Toth ou para a realização adequada da atividade proposta.

O experimento foi desenvolvido em cinco etapas: (I) Familiarização com o ambiente: realizada antes do experimento, com o objetivo de apresentar todos os recursos e modos de funcionamento da ferramenta Toth; (II) Coleta de dados 1 - Desenvolvimento do projeto: foi solicitado que os alunos desenvolvessem projetos dentre 27 palavras-chave definidas pela professora da disciplina sobre o tema "Hardware e Software"; (III) Coleta de dados 2 Aplicação de questionário: após a conclusão da atividade, os alunos foram solicitados a responder um questionário, no intuito de averiguar as percepções dos alunos sobre sua satisfação em relação à ferramenta e a atividade, ao uso dos materiais de apoio, sobre ferramentas de colaboração, e sobre relevância em contribuir com outros projetos e receber contribuições; (IV) Coleta de dados 3 - Entrevista: foi realizada uma entrevista com vistas a compreender de que maneira a professora percebeu a contribuição da atividade para o desenvolvimento dos projetos, tanto no que diz respeito aos aspectos investigativos quanto colaborativos. As respostas obtidas serviram também para confrontar ou confirmar as respostas dos alunos obtidas no questionário; (V) Análise e Triangulação de dados: buscou-se validar os resultados a partir dos diferentes métodos e fontes de coleta. Os aspectos centrais de observação foram: o projeto, a colaboração, a recomendação e a ferramenta/atividade.

\section{Resultados}

Os resultados obtidos através da coleta de dados realizada durante o experimento final buscou investigar de que forma um ambiente de apoio à elaboração de projetos, com recursos de colaboração e recomendação, poderia contribuir em uma atividade de ABPr. A análise dos resultados obtidos no experimento foi dividida em quatro categorias:

\subsection{Análise dos Projetos}

Uma vez concluída a atividade, buscou-se avaliar o trabalho realizado pelos alunos com vistas a compreender, de maneira mais geral, se os recursos da ferramenta Toth contribuíram com o desenvolvimento dos projetos. Para tal, levou-se em consideração a avaliação realizada pela professora responsável pela disciplina. A docente avaliou individualmente cada projeto e atribuiu a eles notas em uma escala de 0 a 10 pontos, de acordo com critérios de avaliação utilizados usualmente em suas correções, como: adequação ao tema, aprofundamento do estudo, consistência argumentativa e correção da linguagem.

A média das notas atribuídas aos projetos dos 40 alunos aptos para esta análise foi de 7,31, sendo que apenas $15 \%$ (6) dos alunos obtiveram notas abaixo da média necessária para aprovação $(6,00)$. Em entrevista realizada com a referida professora, ela comentou sobre o desempenho dos alunos da seguinte forma: "[...] os alunos souberam atender as expectativas da atividade proposta em relação à qualidade e quantidade de texto, bem como na elaboração de projetos adequados ao tema." A docente ainda fez um comparativo com outras atividades realizadas em anos anteriores com turmas do mesmo ano, sem a utilização de uma ferramenta específica para o desenvolvimento de projetos. Ela afirmou que nesta atividade os alunos se mostraram muito mais empenhados e com mais facilidade em entender a proposta de texto que precisava ser elaborado e, diferente de outros anos, uma parcela pequena de alunos ficou com a nota abaixo da média. 
Estas afirmações sustentam a proposta deste trabalho em proporcionar um ambiente para o apoio de atividades de Aprendizagem Baseada em Projetos. Igualmente aos comentários da professora, foi possível observar a dedicação da grande maioria dos alunos durante a realização da atividade, sempre buscando formas de melhorar seus projetos, seja através da busca de informações mais detalhadas sobre o assunto ou através da inclusão de recursos multimídia que pudessem dar mais clareza ao trabalho.

\subsection{Análise da Colaboração}

Durante o desenrolar da atividade, as ações de colaboração entre os alunos foram coletadas no intuito de observar como as interações realizadas através da utilização dos recursos colaborativos disponibilizados na ferramenta, auxiliaram os alunos durante a atividade. Essas interações são fundamentais para que ocorra a troca de conhecimento.

Este tipo de troca entre os alunos pode ser exemplificado pelo comentário da Aluna C1, em um projeto de um colega (Aluno C2) sobre o assunto "Computador". A Aluna C1, ao ler e analisar o texto de seu colega fez o seguinte comentário: "Qual a melhor memória: secundária ou terciária?". Ao se deparar com esse questionamento, o Aluno C2 respondeu o comentário da seguinte forma: "A memória secundária não necessita de operações de montagem [...] para acessar os dados, como discos rígidos; a memória terciária depende das operações de montagem, como discos ópticos e fitas magnéticas, entre outros. ”. Para responder esta pergunta, muito provavelmente o Aluno $\mathrm{C} 2$ precisou investigar novamente sobre seu assunto e, desta forma, ampliou um pouco mais seus conhecimentos.

Nas observações feitas durante o experimento, pode-se notar que ao receberem uma notificação que alguém havia comentado em seu projeto, os alunos imediatamente pausavam o desenvolvimento do trabalho e logo iam ler a contribuição deixada. Em tempos de ampla utilização de redes sociais, o recebimento de uma notificação de que alguém contribuiu em seu projeto pode ser comparada à expectativa de um indivíduo em receber um comentário em uma publicação/postagem sua como, por exemplo, no Facebook (Ellison, Steinfield, \& Lampe, 2007). Isto possibilita que seja considerada a perspectiva de outro colega, com outros pontos de vista e assim, descentralizar o processo de raciocínio do autor do projeto.

Uma das questões do questionário relativa à colaboração refere-se exatamente à opinião dos alunos sobre ler e contribuir com os projetos de seus colegas. Entende-se em que ao ler um projeto de um colega e elaborar um comentário sobre texto, o aluno esteja estimulando seu pensamento crítico sobre um assunto. Os resultados apontaram que 82,5\% dos 40 alunos que participaram desta avaliação deram uma resposta positiva ("Concordo Totalmente" ou "Concordo") sobre o interesse em ler e contribuir com outros projetos (Figura 8). Os outros $17,5 \%$ restantes optaram por uma resposta neutra e nenhum aluno assinalou as opções negativas ("Discordo" ou "Discordo Totalmente"). 


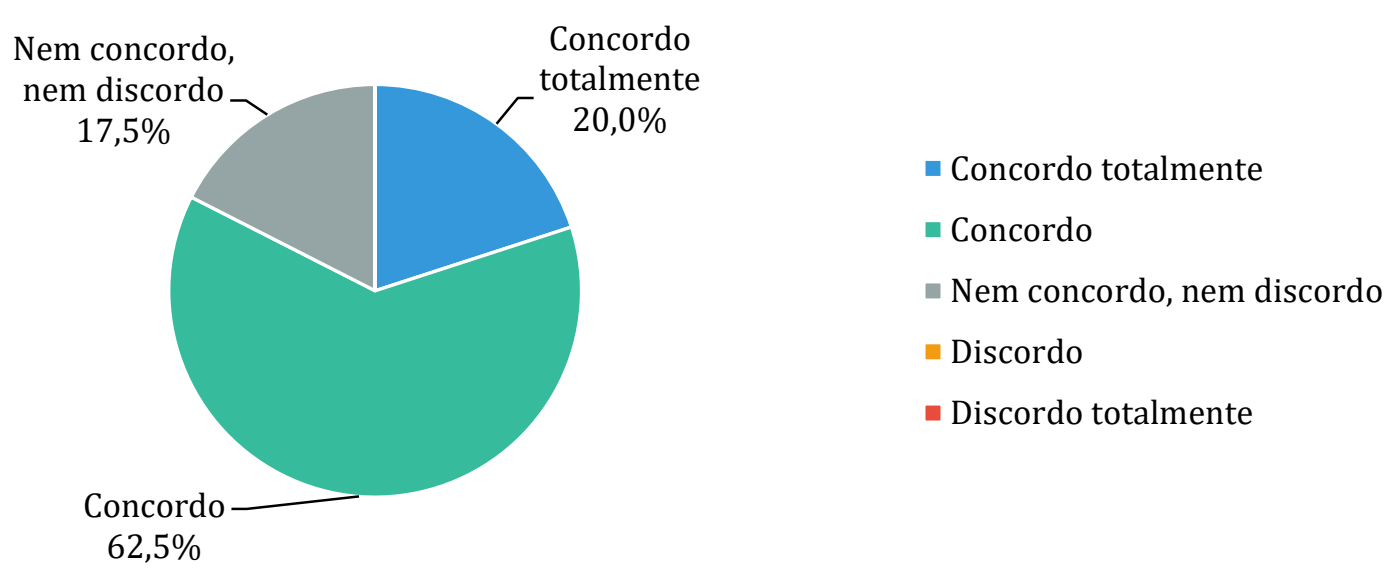

Figura 8: Relevância em ler e contribuir com outros projetos.

Estas ações colaborativas possibilitam que os alunos compreendam não somente o assunto de seu próprio projeto, mas também outros assuntos relacionados ao mesmo tema. Deste modo, este tipo de estratégia em uma atividade proporciona aos alunos que atentem mais ao tema como um todo e não somente a alguns tópicos específicos. Durante a entrevista, a professora comentou sobre a relevância dos alunos terem acesso à leitura e contribuírem em outros projetos, afirmando o seguinte: "[...] foi um processo de troca bem satisfatório e que antes não acontecia com outras turmas". A docente ainda destacou que, por se tratar de uma turma nova com apenas um mês de aulas desde o início do período letivo, ela tinha receio que este tipo de interação não ocorresse, mas para sua surpresa a grande maioria da turma aprovou esta fase da atividade.

A professora também apontou que, em um primeiro momento, alguns alunos demonstraram não estar à vontade com o fato de seus colegas poderem visualizar os seus trabalhos e elaborar comentários sobre ele. Entretanto, ao observarem que outros colegas estavam interagindo através dos comentários e dos demais recursos de comunicação da ferramenta, estes alunos começaram a entender o objetivo da atividade e começaram a interagir com até mesmo colegas que não tinham uma relação tão próxima. Com isto, apenas 4 alunos $(10 \%)$ não escreveram comentários em outros projetos, mas todos os projetos receberam comentários de outros alunos.

\subsection{Análise da Recomendação}

Durante o desenvolvimento dos projetos, os alunos receberam recomendações de materiais de apoio relacionados ao assunto de seus trabalhos. Estes materiais foram sugeridos com o intuito de ampliar a reflexão dos aprendizes durante os processos investigativos propostos pela atividade. Uma das questões desta avaliação indagava se os alunos haviam considerado apropriados os materiais sugeridos para seu projeto e 71,8\% "Concordaram Totalmente" ou "Concordaram" que os itens sugeridos eram apropriados ao assunto de seu projeto. Outros $23,1 \%$ responderam de forma neutra e apenas 2 alunos $(5,1 \%)$ "Discordaram" ou "Discordaram Totalmente" da pertinência dos itens sugerido, conforme ilustrado pelo gráfico da Figura 9. 


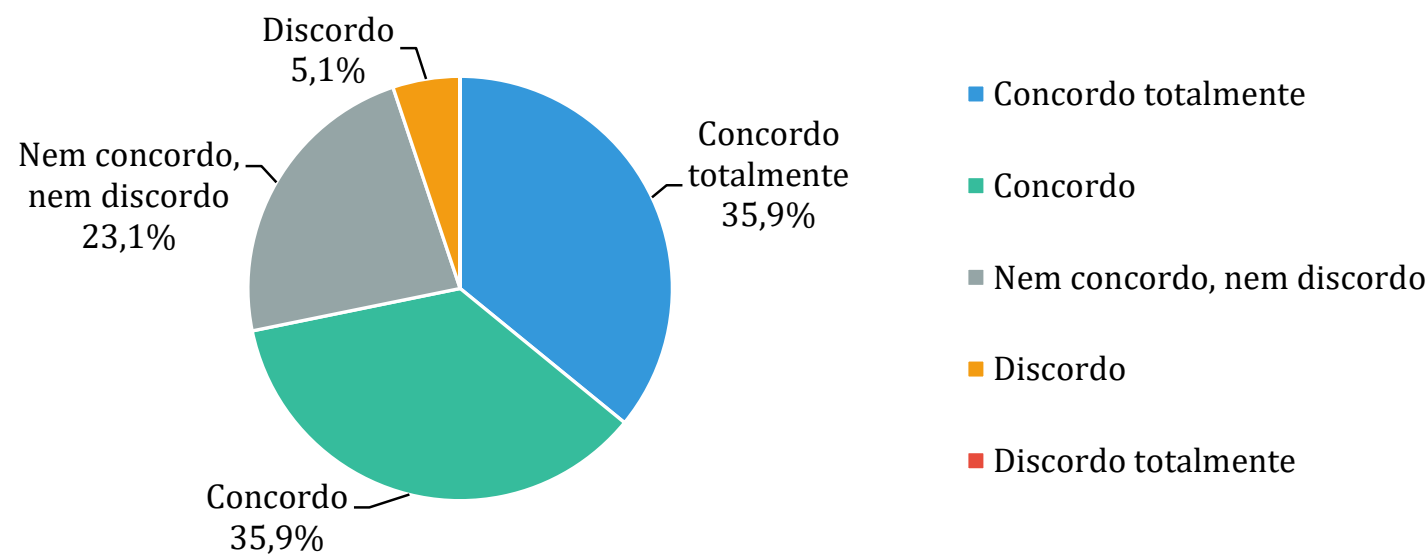

Figura 9: Pertinência dos itens do Material de Apoio.

Nos comentários textuais dos alunos no questionário foi reforçada a ideia de utilidade das recomendações apresentadas pelo sistema. O Aluno R1 fez o seguinte comentário: " [...] As sugestões dadas no lado direito da tela foram muito úteis.". Além disso, a professora destacou que muitos alunos não clicavam na recomendação propriamente dita, mas que os itens sugeridos junto com pequenos pedaços de texto que aparecem logo abaixo da sugestão (snippets), davam um embasamento para que os alunos fizessem suas próprias consultas em mecanismos de busca, ampliando assim a investigação sobre o assunto/tema.

Portanto, os resultados apresentados nesta análise demonstram que a recomendação, em uma atividade de ABPr, tem o potencial de auxiliar os alunos durante suas investigações, levando-os a tomarem decisões que podem levá-lo a outras questões e reflexões.

\subsection{Análise do Nível de Satisfação}

Esta última avaliação visou mensurar o nível de satisfação e de dificuldade dos alunos ao participarem do modelo de atividade proposto, bem como a utilização da ferramenta Toth para a realização das tarefas planejadas. Para isso foram feitas duas perguntas, a primeira sobre o nível de satisfação sobre a atividade realizada e a segunda a utilização da ferramenta para este tipo de atividade. Em ambos os casos, a grande maioria (90,0\% e 92,5\% respectivamente) respondeu que ficou "Muito Satisfeito" ou "Satisfeito" com a atividade/ferramenta. Os demais responderam de forma neutra e não houve alunos que assinalaram como "Insatisfeito" ou "Muito Insatisfeito".

O nível de satisfação é essencial para que os alunos comecem e continuem utilizando recursos tecnológicos em tarefas que contribuam para o aprendizado em sala de aula. A web está cada vez mais acessível a todas as pessoas e conta com uma grande variedade de aplicações. Contudo, observa-se que esta popularidade não implica necessariamente em satisfação dos usuários, que se confrontam muito frequentemente com problemas de usabilidade que podem prejudicar o desempenho e o interesse dos alunos em uma tarefa (Chiu, Hsu, Sun, Lin, \& Sun, 2005). Portanto, a satisfação é um critério importante, embora não o único, para determinação da qualidade global de uma aplicação.

Em uma questão aberta do questionário, a Aluna S1 escreveu o seguinte depoimento: "[...] acabamos aprendendo sobre assuntos que geralmente não pesquisamos [...], é bom compartilhar o que sabemos com nossos colegas e ver também o que eles sabem. Assim acabamos aprendendo todos juntos.". A professora reforçou na entrevista que os alunos estavam se sentindo à vontade com a ferramenta e eufóricos com a atividade, resultando em trabalhos melhores, segundo a docente. Estas constatações, em conjunto com os dados obtidos pelo questionário, reforçam a ideia de que a atividade foi bem recebida pelos alunos. 


\section{Considerações Finais}

O estudo realizado por este trabalho buscou investigar de que modo uma atividade de Aprendizagem Baseada em Projeto, apoiada por um ambiente tecnológico, contribuiu no desenvolvimento de projetos por meio de recursos de recomendação de conteúdo e ferramentas de colaboração. Para isto foi proposto um modelo de atividade que colocasse os alunos diante de uma forma de aprender diferente das utilizadas habitualmente, atrelando diferentes áreas da Educação e da Computação, como a Aprendizagem Ativa, com ênfase na Aprendizagem Baseada em Projetos, a Aprendizagem Colaborativa e os Sistemas de Recomendação.

Com base nestes temas e na análise dos estudos preliminares, foi elaborada uma atividade que pudesse contribuir com o desenvolvimento de projetos, com o suporte de recursos colaborativos e da recomendação de conteúdo. Para que fosse possível a aplicação do modelo em um contexto real, a ferramenta computacional Toth foi desenvolvida com os requisitos necessários para a realização da pesquisa.

O experimento final foi realizado com alunos do ensino médio e foi possível constatar que a atividade proposta foi bem aceita. Isso ficou evidente pelas observações feitas in loco, em que os estudantes mostraram-se focados no desenvolvimento das tarefas propostas. Esta observação também foi confirmada pela professora que ofereceu a oportunidade de experimentação deste estudo, quando ela relata que os alunos estiveram mais empenhados em realizar as tarefas propostas em comparação a atividades similares realizadas anteriormente. A atividade teve duração de um mês e os alunos puderam trabalhar em seus projetos tanto em sala de aula, quanto a distância.

A partir da análise dos resultados obtidos no experimento, pode-se concluir que o modelo de atividade proposto e os recursos implementados na ferramenta Toth, contribuíram de forma significativa para o desenvolvimento de projetos, nos quais a colaboração entre pares teve um papel importante. Isto é evidenciado, primeiramente, pela avaliação sobre os trabalhos produzidos. Segundo o relato da professora, os alunos tiveram um desempenho superior se comparado a anos anteriores, em que não foram utilizadas ferramentas específicas para a realização de projetos. Além disso, os recursos de colaboração criaram um amplo espaço de troca e interação entre os alunos, fazendo que se sentissem implicados tanto no seu próprio processo de aprendizagem quanto na aprendizagem dos demais colegas. Sem a utilização dos recursos tecnológicos disponibilizados pela ferramenta, a interação entre os alunos poderia não ocorrer ou ocorrer em menor escala.

Em relação à sugestão de materiais complementares, a avaliação feita pelos alunos sobre a qualidade e pertinência dos itens recomendados foi positiva. A maior parte dos alunos considerou os materiais de apoio sugeridos durante o desenvolvimento de seus trabalhos apropriados ao assunto. A professora ainda destacou que observou muitos alunos utilizando os resumos dos itens sugeridos como base para os projetos e também para ampliarem suas buscas na web sobre assuntos que eram apresentados no material de apoio. Portanto, pode-se afirmar que os materiais sugeridos durante a escrita do projeto têm potencial para auxiliar os alunos em suas investigações, fazendo com que tomem decisões a partir de informações complementares trazidas pelo sistema de recomendação integrado à ferramenta, de forma específica para o assunto que está sendo desenvolvido.

Com base nestas considerações é possível afirmar que o ambiente de apoio à escrita de projetos (Toth), com recursos de recomendação e colaboração, contribuiu de forma expressiva para o desenvolvimento dos projetos. Além da implementação da ferramenta ter tornado possível a realização dos estudos deste trabalho, ela também deixa uma nova possibilidade aos professores e/ou instituições para sua aplicação em salas de aula ou no ensino a distância. 
A ferramenta encontra-se disponível em duas versões: oficial (http://toth.net.br), utilizada para experimentos em contextos escolares e com restrição de acesso apenas aos envolvidos; e versão de demonstração (http://toth.net.br/demo), com exemplos de temas e projetos e disponível para o público em geral, sendo possível testar todas as funcionalidades e recursos que envolvem uma atividade de desenvolvimento de projetos.

Como trabalhos futuros estão sendo organizados novos testes utilizando a ferramenta Toth em outros contextos de ensino. Uma proposta de envolver diferentes turmas, de cursos diferentes, em uma atividade com um tema interdisciplinar também está sendo idealizada. Acredita-se que desta forma os participantes receberiam comentários com pontos de vista bem distintos aos seus, estimulando-os a pensarem sobre o assunto do projeto a partir de outras perspectivas.

\section{Referências}

Acosta, O., Reategui, E., \& Behar, P. A. (2016, November). Recomendação de Conteúdo em um Ambiente Colaborativo de Aprendizagem Baseada em Projetos. In Anais dos Workshops do Congresso Brasileiro de Informática na Educação (Vol. 5, No. 1, p. 30). doi: 10.5753/cbie.wcbie.2016.30 [GS SEARCH]

Azer, S. A., Peterson, R., Guerrero, A. P., \& Edgren, G. (2012). Twelve tips for constructing problem-based learning cases. Medical teacher, 34(5), 361-367. [GS SEARCH]

Bonwell, C. C., \& Eison, J. A. (1991). Active Learning: Creating Excitement in the Classroom. 1991 ASHE-ERIC Higher Education Reports. ERIC Clearinghouse on Higher Education, The George Washington University, One Dupont Circle, Suite 630, Washington, DC 20036-1183. [GS SEARCH]

Cazella, S. C., Reategui, E. B., \& Behar, P. (2010). Recommendation of learning objects applying collaborative filtering and competencies. In Key Competencies in the Knowledge Society (pp. 35-43). Springer Berlin Heidelberg. [GS SEARCH]

Chiu, C. M., Hsu, M. H., Sun, S. Y., Lin, T. C., \& Sun, P. C. (2005). Usability, quality, value and e-learning continuance decisions. Computers \& Education,45(4), 399-416. [GS $\underline{\text { SEARCH] }}$

Dooly, M. (2008). Telecollaborative language learning: A guidebook to moderating intercultural collaboration online. Peter Lang. [GS SEARCH]

Drachsler, H., Hummel, H. G., \& Koper, R. (2008). Personal recommender systems for learners in lifelong learning networks: the requirements, techniques and model. International Journal of Learning Technology, 3(4), 404-423. [GS SEARCH]

Ellison, N. B., Steinfield, C., \& Lampe, C. (2007). The benefits of Facebook "friends:" Social capital and college students' use of online social network sites. Journal of ComputerMediated Communication, 12(4), 1143-1168. [GS SEARCH]

Fong, M. A., O’Toole, M. J., \& Keppel, M. (2007). The attitude of teacher educators to the use of problem based learning: the video triggers approach. Proceedings Ascilite Singapore, 603-619. [GS SEARCH]

Google Custom Search (2017). Recuperado de: https://developers.google.com/custom-search/

Gormally, C., Brickman, P., Hallar, B., \& Armstrong, N. (2009). Effects of inquiry-based learning on students' science literacy skills and confidence. International journal for the scholarship of teaching and learning, 3(2), 16. [GS SEARCH] 
Gosper, M., Malfroy, J., \& McKenzie, J. (2013). Students' experiences and expectations of technologies: An Australian study designed to inform planning and development decisions. Australasian Journal of Educational Technology, 29(2). [GS SEARCH]

Guitert, M., \& Giménez, F. (2000). Trabajo cooperativo en entornos virtuales de aprendizaje. Aprender en la virtualidad, 10, 10-18. [GS SEARCH]

Harasim, L., Teles, L., Turoff, M., \& Hiltz, S. R. (2005). Redes de aprendizagem: um guia para ensino e aprendizagem on-line. São Paulo: Senac. [GS SEARCH]

Kirschner, P. A., Sweller, J., \& Clark, R. E. (2006). Why minimal guidance during instruction does not work: An analysis of the failure of constructivist, discovery, problem-based, experiential, and inquiry-based teaching. Educational psychologist, 41(2), 75-86. [GS $\underline{\mathrm{SEARCH}}]$

Larmer, J., \& Mergendoller, J. R. (2010). Seven essentials for project-based learning. Educational leadership, 68(1), 34-37. [GS SEARCH]

Lefrançois, G. R. (2008). Análise, síntese e integração. Teorias da aprendizagem, 5 ed. Tradução: Vera Magyar. São Paulo: Cengage Learning. [GS SEARCH]

Lévy, P. (1999). Cibercultura. 1a edição. São Paulo: Editora, 34. [GS SEARCH]

Logtenberg, A., Van Boxtel, C., \& van Hout-Wolters, B. (2011). Stimulating situational interest and student questioning through three types of historical introductory texts. European Journal of Psychology of Education, 26(2), 179-198. [GS SEARCH]

Markham, T., Larmer, J., \& Ravitz, J. (2008). Project Based Learning HandBook - A Guide to Standards-focused Project based learning, BIE-Buck Institute for Education. [GS SEARCH]

Markham, T. (2012). Project Based Learning: Design and Coaching Guide: Expert Tools for Innovation and Inquiry for K-12 Educators. [GS SEARCH]

Meurer, H. (2014). Ferramenta de gerenciamento e recomendação como recurso na aprendizagem baseada em projeto em design. Tese de Doutorado. Universidade Federal do Rio Grande do Sul. Recuperado de: http://www.lume.ufrgs.br/handle/10183/115721

Michael, J. (2006). Where's the evidence that active learning works? Advances in physiology education, 30(4), 159-167. [GS SEARCH]

Palloff, R. M., \& Pratt, K. (2004). O aluno virtual-um guia para trabalhar com estudantes online. Penso Editora. [GS SEARCH]

Piaget, J. (1973). As operações lógicas e a vida social. Estudos sociológicos, 164-193. [GS $\underline{\mathrm{SEARCH}}]$

Piaget, J. (1977). The role of action in the development of thinking. InKnowledge and development (pp. 17-42). Springer US. [GS SEARCH]

Rafaeli, S., Dan-Gur, Y., \& Barak, M. (2008). Social recommender systems: recommendations in support of e-learning. In Online and Distance Learning: Concepts, Methodologies, Tools, and Applications (pp. 2432-2448). IGI Global. [GS SEARCH]

Reategui, E., Boff, E., \& Campbell, J. A. (2008). Personalization in an interactive learning environment through a virtual character. Computers \& Education, 51(2), 530-544. [GS $\underline{\text { SEARCH] }}$

Reategui, E., Epstein, D., Lorenzatti, A., \& Klemann, M. (2011, July). Sobek: A text mining tool for educational applications. In International Conference on Data Mining (pp. 59-64). [GS SEARCH] 
Reategui, E., \& Epstein, D. (2015). Automatic Extraction of Nonlinguistic Representations of Texts to Support Writing. American Journal of Educational Research, 3(12), 1592-1596. [GS SEARCH]

Resnick, P., \& Varian, H. R. (1997). Recommender systems. Communications of the $A C M, 40(3), 56-58$. [GS SEARCH]

Ricci, F., Rokach, L., \& Shapira, B. (2015). Recommender systems: Introduction and challenges. In Recommender Systems Handbook (pp. 1-34). Springer US. [GS SEARCH]

Rifon, L. E. A., Rodriguez, A. C., Roris, V. M. A., Gago, J. M. S., \& Iglesias, M. J. F. (2013, April). A recommender system for educational resources in specific learning contexts. In Computer Science \& Education (ICCSE), 2013 8th International Conference on (pp. 371-376). IEEE. [GS SEARCH]

Seol, S., Sharp, A., \& Kim, P. (2011, July). Stanford Mobile Inquiry-based Learning Environment (SMILE): using mobile phones to promote student inquires in the elementary classroom. In Proceedings of the 2011 International conference on frontiers in education: Computer science \& computer engineering (pp. 270-276). [GS SEARCH]

Soller, A. (2001). Supporting social interaction in an intelligent collaborative learning system. International Journal of Artificial Intelligence in Education (IJAIED), 12, 40-62. [GS SEARCH]

Shuib, N. L. M., Baiti, N., Normadhi, A., Alias, L., \& Binti, N. (2015). Collaborative Recommender System: A Review. International Journal of Advances in Computer Science $\&$ Its Applications. [GS SEARCH] 